\title{
Comparison of coated and uncoated carbide drill bits for drilling titanium grade 2 material
}

\author{
B. Suresh kumar*, V. Vijayan**, N. Baskar*** \\ *K. Ramakrishnan College of Technology, Tiruchirappalli, Tamilnadu, India-621 112, E-mail: bsureshcvl@gmail.com \\ **K. Ramakrishnan College of Technology, Tiruchirappalli, Tamilnadu, India-621 112, E-mail: vijayan.me@gmail.com \\ ***Saranathan College of Engineering, Tiruchirappalli, Tamilnadu, India-Pin 620 012, \\ E-mail: baskarnaresh@yahoo.co.in
}

cross $^{\text {ref }}$ http://dx.doi.org/10.5755/j01.mech.22.6.13467

\section{Introduction}

Manufacturing of components from casting, forging, welding and forming needs machining operation with close tolerance requirement for assembling purposes. In response, a lot of machining operations like turning, milling, grinding and drilling are utilized in manufacturing industries. Drilling is a machining processes, which is used to make a hole on component face. In view of this drilling is one of the important machining processes and has a considerable economical importance. Because it is usually among final steps in the machining of components [1]. When machining a corner, the contact area of cutting tools and work piece varies rapidly which can cause the machining force to suddenly increase generating vibration in the cutting tool, work piece and machine tools. Which reduces the tool life and accuracy of the machined component [2]. Monitoring of tool wear via vibration is very important [3]. So this work concentrates on study about vibration, tool wear and accuracy of machined component. However, Drilling is a highly demanding machining process due to a) complex tool geometry and b) progressive material failure on the work piece [4]. More over the manufacturing of deep holes with small diameter has to face problems to evacuate chips, this introduces frequent problems like incremental torque, tool failure and poor hole quality [5-6].

Now a day's various newer materials are introduced in modern manufacturing industries due to its inherent properties. Hence titanium alloy is one of the newer materials due to its low weight to strength ratio and corrosion resistance properties. But it has poor machinability due to its poor thermal conductivity. So the analysis of drilling parameters on titanium alloy is very important. And this investigation is the extension of research in drilling of titanium alloy Ti-6Al-4V to titanium grade 2 alloys [7]. Earlier titanium drilling works concentrated on tool wear and tool temperature [8]. So this work analyses the other responses like machine tool vibration, thrust force, torque, machining time, burr dimensions and surface roughness during drilling operation. The extensive research work carried out in drilling operation with different coated and uncoated drill and work piece combinations [9-12].

Previous works were concentrated in a) coated and uncoated drills effects on tool wear and surface roughness, b) effect of spindle speed and feed rate on burr dimensions, c) effect of thrust force and torque on tool life individually. However this work additionally analyzes the vibration of machine tool during the drilling operation. The performances of coated and uncoated drill bits on different responses were compared and the effectiveness was tested.

\section{Experimental procedure}

An SB. 265 Titanium grade 2 alloy material was used as a work piece material. The chemical elements and percentage of elements are $\mathrm{C}-0.02 \%$, Iron $-0.012 \%$ and $\mathrm{Ti}$ $-99.76 \%$. The work piece is a circular plate diameter $43 \mathrm{~mm}$ and $10 \mathrm{~mm}$ thickness. The work piece is cut by using electrical discharge wire cut machining before clamped on drill tool dynamometer. Then the drill tool dynamometer was fitted on machine table by using $\mathrm{T}-$ slots. Drilling tests were carried out on a LEADWELL make CNC machining center with varying spindle speeds of 12 to $6000 \mathrm{rpm}$. The feed rate was varied in the range of $0.038,0.076$ and $0.203 \mathrm{~mm} / \mathrm{rev}$. Drilling experiments were carried out without coolant.

The drills used in the experiments were uncoated and TiAlN coated solid carbide drills of $6 \mathrm{~mm}$ diameter. The number of drilling experiments was conducted based on 32 factorial designs. So each experiment consist of 9 trials with 2 replicates, totally 18 experiments were conducted for each tool. The number of experimental run and ranges of parameter considered for the experiments as shown in Table.

Table 1

Experimental run and parameter ranges for experiment

\begin{tabular}{|c|c|c|}
\hline Experimental run & Spindle speed & Feed rate \\
\hline 1 & 132 & 0.038 \\
\hline 2 & 132 & 0.076 \\
\hline 3 & 132 & 0.203 \\
\hline 4 & 175 & 0.038 \\
\hline 5 & 175 & 0.076 \\
\hline 6 & 175 & 0.203 \\
\hline 7 & 220 & 0.038 \\
\hline 8 & 220 & 0.076 \\
\hline 9 & 220 & 0.203 \\
\hline
\end{tabular}

The vibration was measured by piezo electric accelerometer located on the machine tool spindle. The thrust force and torque was measured by armed wheel type strain gauge based drill tool dynamometer. Machining time was measured from NC program running time. Burr height was measured by using mechanical comparator with $0.01 \mathrm{~mm}$ least count dial gauge and granite Table. 
The V-block was used to locate the job on granite table. Burr thickness was measured by using Tool Maker's microscope with 30X magnification, $8 \mathrm{~mm}$ diameter field of view and working distance of $80 \mathrm{~mm}$. The surface roughness of the job was measured by using the surface roughness tester of Mitutoyo make and SJP 210P.

\section{Results and discussion}

The experimental results were discussed based on the machine tool vibration, thrust force and torque, burr dimensions and surface roughness.

\subsection{Machine tool vibration}

The experimental machine tool vibration obtained for both TiAlN coated and uncoated carbide drills operated

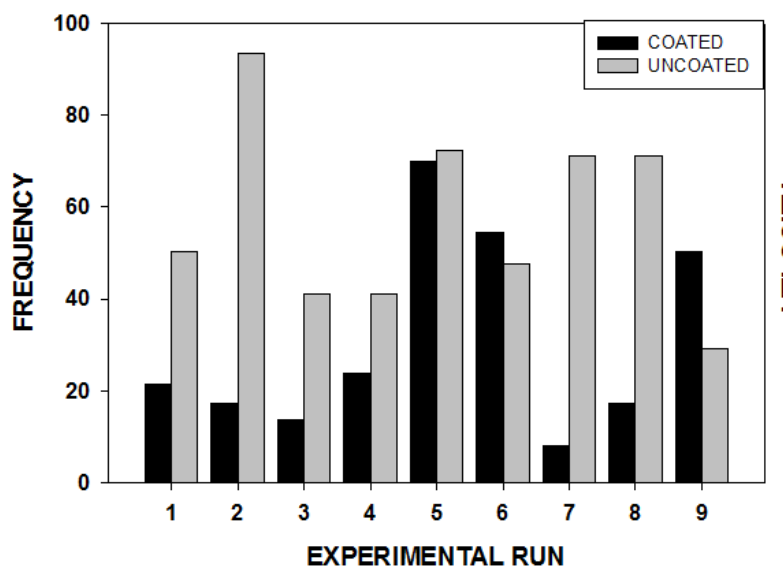

a

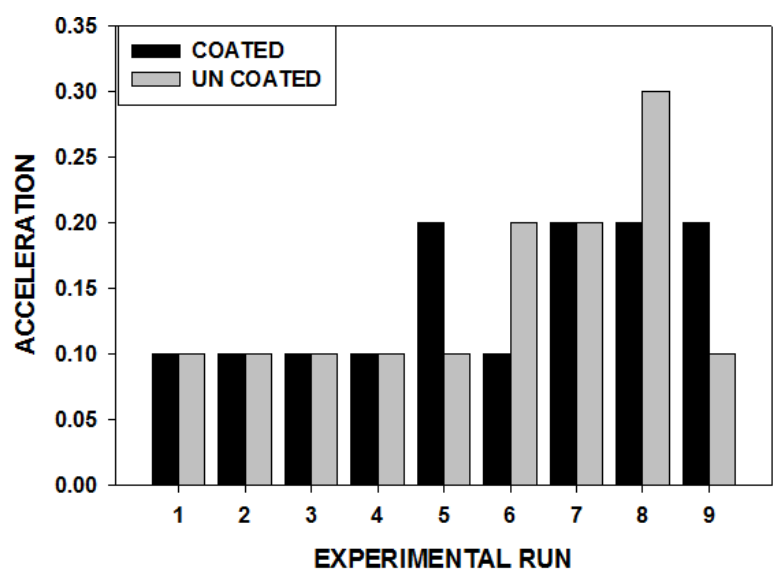

c at various spindle speeds and feed rates are shown in Fig. 1, a-d. The frequency was observed when drilling titanium grade 2 alloy, the frequency was increased at lower cutting speed of $132 \mathrm{rpm}$ and $0.076 \mathrm{~mm} / \mathrm{rev}$ with uncoated drill bit. But drilling with TiAlN coated drill bit, the frequency was increased with spindle speed of $175 \mathrm{rpm}$ and $0.076 \mathrm{~mm} / \mathrm{rev}$ of feed rate. However higher spindle speed with lower feed rate and lower cutting speed and higher feed rate generates minimal frequency with TiAlN coated carbide drill bits subsequently higher spindle speed with higher feed rate produces lesser frequency with uncoated drill bit. Another contributing response is vibration of velocity, the minimum velocity was observed at spindle speed of $175 \mathrm{rpm}$ with $0.076 \mathrm{~mm} / \mathrm{rev}$ feed rate. The acceleration of vibration is same for both tools. The coated drill bits generated higher acceleration as compared to uncoated drill bits.

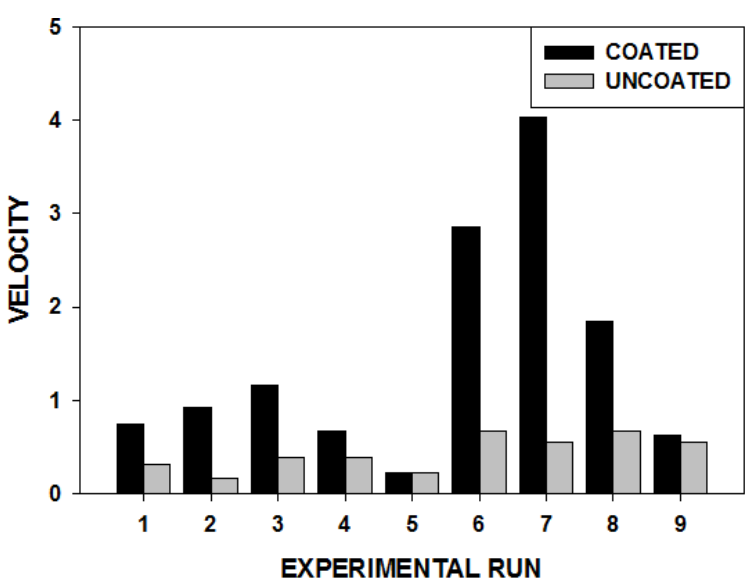

$\mathrm{b}$

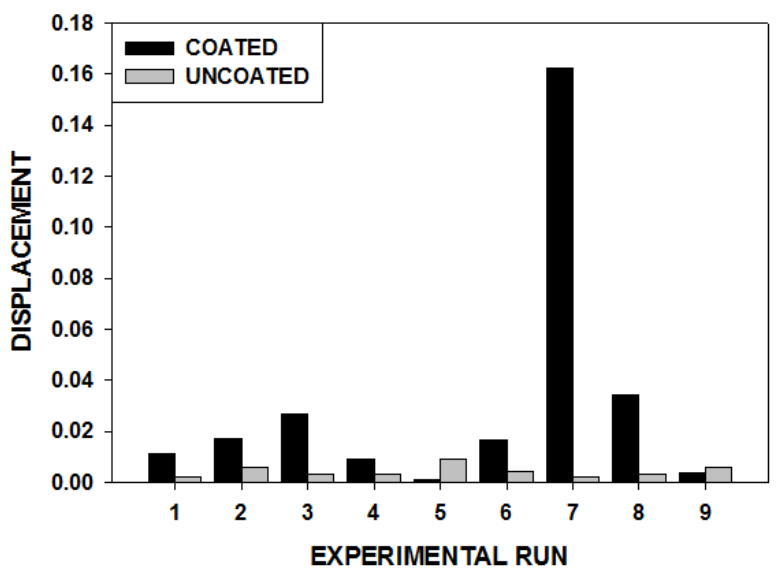

d

Fig. 1 Machine tool vibration when drilling titanium grade 2 alloy using TiAlN coated and uncoated drill at various spindle speed and feed rate: a - frequency Vs Experimental run; b - velocity Vs Experimental run; c - acceleration Vs Experimental run; d - displacement Vs Experimental run

\subsection{Thrust force and torque}

The observed thrust force and torque values are shown in Fig. 2, a and b. The thrust force was larger in higher spindle speed of $220 \mathrm{rpm}$ with $0.036 \mathrm{~mm} / \mathrm{rev}$ of feed rate for TiAlN coated carbide drill bit. Likewise for uncoated carbide drill bits, the higher thrust force was observed at lower spindle speed of $132 \mathrm{rpm}$ with higher feed rate of $0.203 \mathrm{~mm} / \mathrm{rev}$. Subsequently the higher torque is produced by coated carbide drill bits than uncoated drill bits at $175 \mathrm{rpm}$ of spindle speed with $0.203 \mathrm{~mm} / \mathrm{rev}$ of feed rate.

\subsection{Burr dimensions}

Results on burr dimension when drilling uncoated and TiAlN coated carbide drills are shown in Fig. 3, a - d. Uncoated drill recorded minimum entry burr thickness, the entire below $0.2 \mathrm{~mm}$ for all combination of spindle speed and feed rate. The maximum entry burr thickness for uncoated was $0.12 \mathrm{~mm}$ occurred at $175 \mathrm{rpm}$ and $0.076 \mathrm{~mm} / \mathrm{rev}$ of feed rate. And for coated was $0.16 \mathrm{~mm}$ occurred at $132 \mathrm{rpm}$ and $0.076 \mathrm{~mm} / \mathrm{rev}$ of feed rate. 
Lowering the cutting speed and feed rate reduces the entry burr thickness for uncoated drill bit. Exit burr thickness was higher when drilling titanium grade 2 alloy by using coated drill bit. The maximum exit burr thickness for coated drill bit was $0.20 \mathrm{~mm}$ and lowering the cutting speed reduced the exit burr thickness. Increasing the spindle speed tends to decrease the exit burr thickness for coated drill bit. However at the lower spindle speed of $132 \mathrm{rpm}$ with higher feed rate of $0.203 \mathrm{~mm} / \mathrm{rev}$, the exit burr thickness dropped significantly to $0.04 \mathrm{~mm}$. The experimental results shown

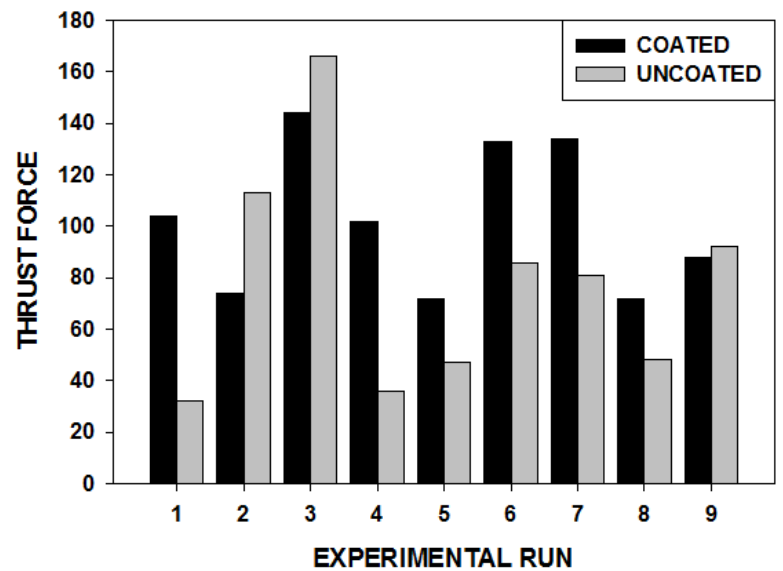

a that uncoated drill bit made good performance than coated drill bit for entry and exit burr thickness. For considering burr height, both entry and exit of the hole were maximum when drilling titanium grade 2 alloy by using coated drill bit. The maximum entry burr thickness and exit burr thickness were recorded 0.10 and $0.63 \mathrm{~mm}$ respectively. Increased spindle speed and feed rate are increased the entry and exit burr height for coated drill bit. There it can be suggested that coated drill bit should not be used for minimizing the burr dimensions.

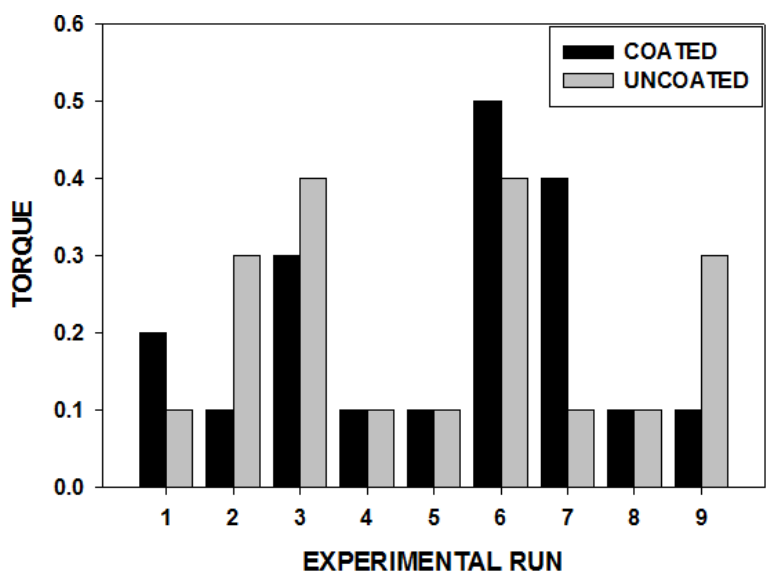

$\mathrm{b}$

Fig. 2 Thrust force and torque when drilling titanium grade 2 alloy using TiAlN coated and uncoated drill: a - thrust force Vs Experimental run, b - torque Vs Experimental run

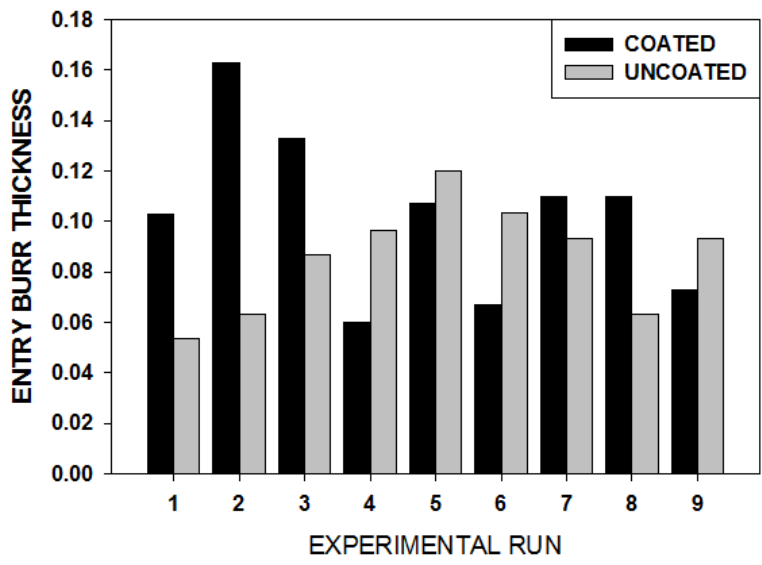

a

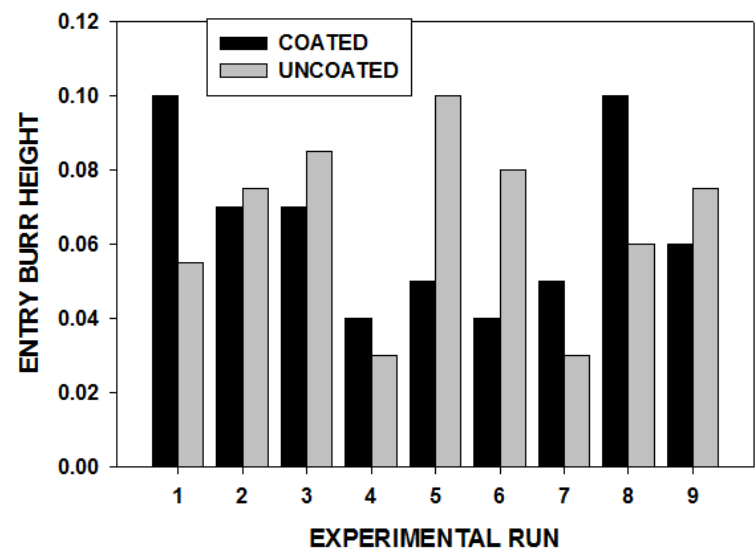

c

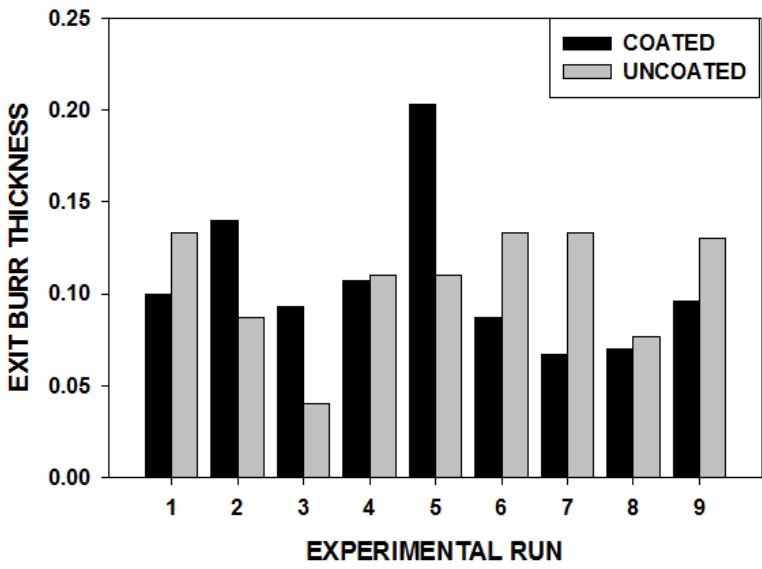

b

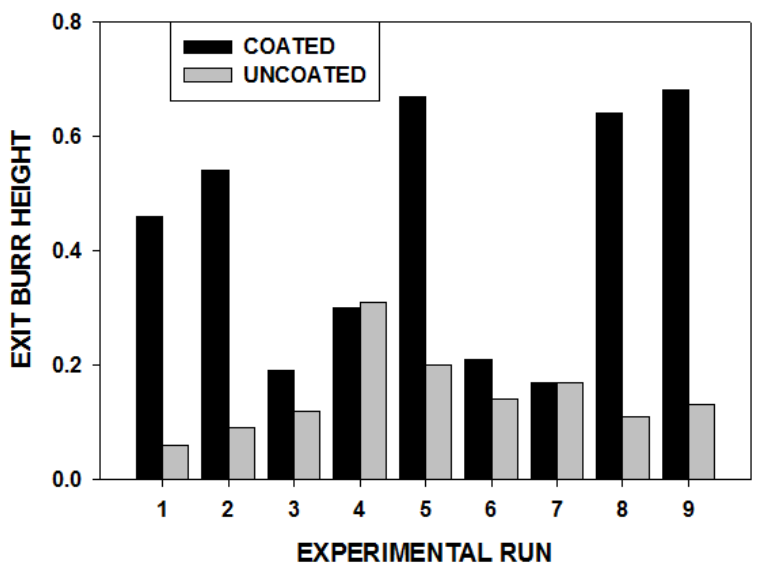

d

Fig. 3 Burr dimensions: a - entry burr thickness Vs Experimental run; b-exit burr thickness Vs Experimental run; c - entry burr height Vs Experimental run; d - exit burr height Vs Experimental 


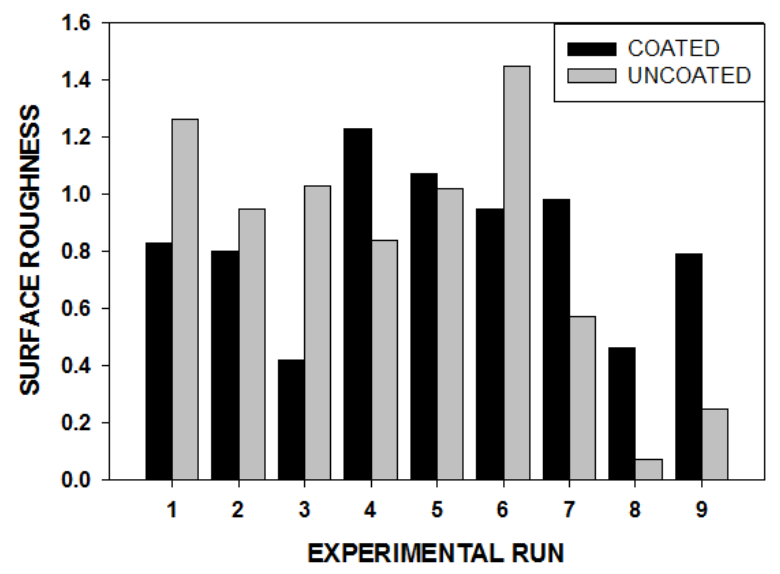

Fig. 4 Surface roughness

\subsection{Surface roughness}

The Fig. 4 shows the surface roughness values when drilling titanium grade 2 alloy with TiAlN coated and uncoated drill bit. It is evident that uncoated drill bit produced poor surface finish than TiAlN coated drill bit. The surface finish $(\mathrm{Ra})$ values achieved for coated drill bit be positioned between 0.4 to $1.25 \mu \mathrm{m}$, while for the uncoated drill bit range was between 0.1 to $1.43 \mu \mathrm{m}$. The lower spindle speed affects the surface finish of drilled hole for both the drill bits. The surface roughness value was maximum at $175 \mathrm{rpm}$ with $0.203 \mathrm{~mm} / \mathrm{rev}$ of feed rate for uncoated drill bit. The maximum surface roughness recorded was $1.23 \mu \mathrm{m}$ at $175 \mathrm{rpm}$ with $0.038 \mathrm{~mm} / \mathrm{rev}$ of feed rate. The maximum frequency of vibration affected the surface finish value for both coated and uncoated drill bits as compared with 4, 5 and 6thexperimental run in Fig. 2 with experimental run of 4, 5 and 6 of Fig. 4.

\section{Conclusions}

The main conclusions drawn from this experimental investigation is as follows:

1. The uncoated drill bit produces the higher frequency of vibration at low spindle speed with mid-level of feed rate than TiAlN coated drill bit. For most combination of spindle speed and feed rate the uncoated drill bit were recorded higher frequency of vibration.

2 . The higher thrust force occurred with uncoated drill bit with the combination of lower spindle speed and higher feed rate in differently higher torque take place with TiAlN coated drill bit at the mid-level of spindle speed with the higher feed rate.

3. TiAlN coated drill bit is not suitable for minimizing the burr dimensions.

4. TiAlN coated drill bit is well suited for surface roughness when drilling SB 265 titanium grade 2 alloy than uncoated drill bit.

\section{References}

1. Rui Li; Parag Hegde; Albert J. Shih. 2007. Highthroughput drilling of titanium alloys, International Journal of Machine Tools \& Manufacture 47: 63-74. http://dx.doi.org/10.1016/j.ijmachtools.2006.02.012.

2. Xianli Liu; Yun-Ding; Caixu Yue; Rui Zhang; Xin Tong. 2015. Off-line feedrate optimization with multiple constraints for corner milling of a cavity,Int. J. Adv. Manuf. Technol. 82: 1899-1907.

http://dx.doi.org/10.1007/s00170-015-7469-4.

3. Mohamed Khemissi Babouri, Nouredine Ouela, Abderrazek Djebala. 2015. Experimental study of tool life transition and wear monitoring in turning operation using a hybrid method based on wavelet multi-resolution analysis and empirical mode decomposition, Int. J. Adv. Manuf. Technol. 82: 2017-2028. http://dx.doi.org/10.1007/s00170-015-7530-3.

4. Ozden Isbilir; Elaheh Ghassemieh. 2011. Finite element analysis of drilling of titanium alloy, Procedia Engineering 10: 1877-1882. http://dx.doi.org/10.1016/j.proeng.2011.04.312.

5. Guibert, N.; Parisa, H.; Rech, J. 2008. A numerical simulator to predict the dynamical behavior of the self vobratory drilling head, International Journal of Machine Tools and Manufacture 48(6): 644-655. http://dx.doi.org/10.1016/j.ijmachtools.2007.11.003.

6. Batzer, S.A; Haan, D.M.; Rao, P.D.; Olson, W.W; Sutherland, J.W. 1998. Chip morphology and hole surface texture in the drilling of cast Aluminum alloys, Journal of Materials Processing Technology 79: 72-78. http://dx.doi.org/10.1016/S0924-0136(97)00324-5.

7. Sharif, S.; Rahim, E.A. 2007. Performance of coated and uncoated-carbide tools when drilling titanium alloy - Ti-6Al4V, Journal of Material Processing Technology 185: 72-76. http://dx.doi.org/10.1016/j.jmatprotec.2006.03.142.

8. Rui Li; Albert J. Shih. 2007. Tool temperature in titanium drilling, Journal of Manufacturing Science and Engineering 129: 740-749. http://dx.doi.org/10.1115/1.2738120.

9. Rotberg, J.; Lenz, E.; Levin, M. 1998. Drill and Clamping Interface in High-Performance Drilling, Int. J. Adv. Manuf. Technol. 14: 229-238. http://dx.doi.org/10.1007/BF01199877.

10. Rivero, A.; Aramendi, G.; Herranz, S.; Lo'pez de Lacalle, L.N. 2006. An experimental investigation of the effect of coatings and cutting parameters on the dry drilling performance of aluminium alloys; Int. J. Adv. Manuf. Technol. 28: 1-11. http://dx.doi.org/10.1007/s00170-004-2349-3.

11. Shusheng Bi; Jie Liang. 2010. Experimental studies and optimization of process parameters for burrs in dry drilling of stacked metal materials, Int. J. Adv. Manuf. Technol. 53(9): 867-876. 
http://dx.doi.org/10.1007/s00170-010-2877-y.

12. Tsao, C.C; Hocheng, H. 2008. Evaluation of thrust force and surface roughness in drilling composite material using Taguchi analysis and neural network, Journal of Materials Processing Technology 203: 342348.

http://dx.doi.org/10.1016/j.jmatprotec.2006.04.126.
B. Suresh kumar, V. Vijayan, N. Baskar

COMPARISON OF COATED AND UNCOATED

CARBIDE DRILL BITS FOR DRILLING TITANIUM

GRADE 2 MATERIAL

S u m mary

The performance of TiAlN coated and uncoated carbide drill bits when drilling titanium alloy were investigated on vibration, thrust force, torque, machining time, burr dimensions and surface roughness. In response, the experiments were carried out on CNC vertical milling machine with two factors and each factor consists of three levels. For experimentation, the ranges of spindle speed and feed rate selection is based on tool manufacturer recommendations. In addition, the effects of spindle speed and feed rate on considered responses were explored and the same is presented in this paper.

Keywords: drilling, uncoated and TiAlN coated drill bit, vibration, thrust force, torque, burr dimensions, surface roughness.

Received October 31, 2015

Accepted November 25, 2016 